\title{
Исследование влияния фитогормона кинетина на состав свободных жирных кислот растений кукурузы в условиях гипоксического стресса методом газожидкостной хроматографии
}

\author{
(С) 2019 Ершова А.Н. ${ }^{1}$, Стерлигова И.А. ${ }^{2}$ \\ ${ }^{1}$ ФББОУ ВО «Воронежский государственньй педагогический университет», Воронеж \\ ${ }^{2}$ ФГБОУ ВО «Воронежский государственный университет», Воронеж
}

Поступила в редакцию 10.07.2019 г.

DOI: $10.17308 /$ sorpchrom.2019.19/2241

\begin{abstract}
Свободные жирные кислоты растений кукурузы метилировали диазометаном. Газохроматографический анализ метиловых эфиров жирных кислот показал, что доминирующими были миристиновая (С14:0), пальмитиновая (С16:0), пальмитолеиновая (С16:1) и линолевая кислоты (C18:2). При гипоксии в клетках отмечалось накопление С16:1 и С18:2, что увеличивало уровень ненасыщенности $(\mathrm{u} / \mathrm{s})$. Подобное действие оказывала и $\mathrm{CO}_{2}$-среда. Предобработка проростков кинетином предотвращала накопление ненасыщенных жирных кислот, нормализуя уровень их насыщенности. Предполагается, что кинетин способен тормозить распад фосфолипидов и их перекисное окисление, что повышает устойчивость к действию гипоксии и СО2-среды.
\end{abstract}

Ключевые слова: свободные жирные кислоты, газожидкостная хроматография, проростки кукурузы, кинетин, гипоксия, $\mathrm{CO}_{2}$-среда

\section{Study of phytohormone kinetin effect on free fatty acids composition in maize plants under hypoxic stress by gas-liquid chromatography method}

\author{
(C) 2019 Ershova A.N. ${ }^{1}$, Sterligova I.A. ${ }^{2}$ \\ ${ }^{1}$ Voronezh State Pedagogical University, Voronezh \\ ${ }^{2}$ Voronezh State University, Voronezh
}

\begin{abstract}
Effect of phytohormone kinetin on composition change of free fatty acids of maize plants under different aeration (air, hypoxia, $\mathrm{CO}_{2}$-media) was studied. Free fatty acids were extracted after transfer to potassium salts. By gas-liquid chromatography method it was discovered that maize seedlings contain almost all free fatty acids specific to phospholipids of plant cells. An exception was oleic acid which was detected in trace amount. The dominating ones among free fatty acids of maize seedlings were saturated C16:0 palmitic and unsaturated $\mathrm{C} 16: 1$ palmitoleic acids ( 23.5 and $16.11 \%$ respectively). Plant treatment by kinetin induced changes among free fatty acids of seedlings but did not affect their qualitative composition. Under hypoxia and especially under $\mathrm{CO}_{2}$-media the accumulation of unsaturated fatty acids (palmitoleic and linoleic) was observed which resulted in increase of their unsaturation level $(\mathrm{u} / \mathrm{s})$ from 0.57 to 0.60 and 0.79 respectively. Pre-treatment by kinetin prevented the observed changes in free fatty acids content in plants placed under modified gas media and largely limited linoleic acid accumulation. At the same time under kinetin the content of monoenoic unsaturated fatty acids was increasing. This resulted in decrease of unsaturated free fatty acids $(\mathrm{u} / \mathrm{s})$ till 0.60 and 0.54 which was close to aerated plants.
\end{abstract}


We showed that kinetin prevents degradation of phospholipids, free fatty acids accumulation and their peroxidation which were only assumptions before. It is necessary to note that stabilizing effect of kinetin was observed in seedlings under normal hypoxia and under high concentrations of carbon dioxide. This fact shows that effect of high concentrations of carbon dioxide on fatty acids exchange is easily reversible and can be cancelled by kinetin treatment of plants or return to normal aeration. Assumed that phytohormone kinetin can inhibit a breakdown of phospholipids and their peroxidation which increases tolerance of seedlings to hypoxia and $\mathrm{CO}_{2}$-media.

Keywords: free fatty acids, gas-liquid chromatography, maize seedlings, kinetin, hypoxia, $\mathrm{CO}_{2}$ media

\section{Введение}

Фитогормоны участвуют в регуляции реакций растений на стрессы. Показано[1], что фитогормоны цитокинины способны повышать холодо- и теплоустойчивость, замедлять проявление признаков водного стресса и старение. Отмечено, что под влиянием кинетина в условиях гипоксического стресса предотвращаются изменения внутриклеточного распределения вторичных соединений и аминокислот [2]. Показано влияние кинетина на различные стороны обмена веществ в клетках растений, в частности на активность ферментов, например липоксигеназы [3], участвующей в процессах окисления свободных жирных кислот. В то же время образование свободных жирных кислот тесно связано с превращением фосфолипидов [4], являющихся основными компонентами биологических мембран. Ранее нами было показано [5], что при действии на растения условий кратковременной гипоксии повышалась степень ненасыщенности свободных жирных кислот митохондрий за счет возрастания содержания пальмитолеиновой и линолевой кислот. Однако остался не выясненным вопрос о возможном влиянии фитогормонов, в частности кинетина, на свободные жирные кислоты растений при аэрации и дефиците кислорода (гипоксия). При этом совсем не анализировалось действие кинетина на свободные жирные кислоты проростков в условиях действия высоких концентраций диоксида углерода, который обладает специфическим влиянием на обменные процессы растений, выступая в роли тригерного механизма [6], запускающего каскад адаптационных процессов у растений при недостатке кислорода. В связи с этим провели изучение влияния фитогормона кинетина на состав свободных жирных кислот растений кукурузы, которые подвергались воздействию разных газовых сред.

\section{Эксперимент}

В качестве объекта исследования были выбраны проростки кукурузы (Воронежская 76), выращенные методом гидропоники. В этиолированные проростки без корней и семядолей методом насасывания с транспирационным током в течение 12 ч вводили раствор кинетина $(10$ мг/дм³ $)$ и помещали на 9 часов в затемненные вакуумэксикаторы, через которые пропускали разные газовые среды: воздух (контроль), азот (содержание кислорода $0.5 \% \mathrm{v} / \mathrm{v}$ ) и углекислый газ (из баллонов). Выбранная экспозиция соответствовала наибольшим изменениям в составе свободных жирных кислот митохондрий проростков кукурузы, которые наблюдались в проведенных нами ранее опытах по исследованию влияния разных сроков действия гипоксии [5].

Выделения свободных жирных кислот проводили модернизированным нами методом [5] после экстрагированиям смесью гексан:изопропанол $(3: 2)$ в присутствии антиоксиданта ионола $(0.001 \%)$. Для отделения водорастворимых примесей экстракт обрабатывали $1 \% \mathrm{Na}_{2} \mathrm{SO}_{4}$. K экстракту добавляли двойной объем $0.05 \mathrm{H}$ калийной щелочи и через 1-2 мин изопропанол. Верхний слой, содержащий свободные жир- 
ные кислоты в виде калийных солей, отмывали петролейным эфиром и подкисляли $15 \% \mathrm{HCl}$ до $\mathrm{pH} 2.0$. Свободные жирные кислоты экстрагировали петролейным эфиром, полученный экстракт упаривали в токе азота [5] и растворяли в гексане.

Метилирование жирных кислот проводили с использованием диазометана, который получали в замкнутой системе. Диазометан током сухого воздуха направляли в пробирку, содержащую растворенные в гексане жирные кислоты. Об окончании метилирования судили по образованию стойкой желтой окраски раствора. Объем пробы метиловых эфиров жирных кислот доводили до 0.5-1.0 см³ продуванием тока азота.

Метиловые эфиры жирных кислот анализировали методом газожидкостной хроматографии на хроматографе «Chrom 42» (Чехия) с пламенно-ионизационным детектором и колонкой 2.5 м, заполненной $10 \%$ полиэтиленгликольсукцинатом на хроматоне N-AW («Chemapol», Чехия). Температура камеры испарения составляла $220^{\circ} \mathrm{C}$, термостата $-190^{\circ} \mathrm{C}$. Скорость газа носителя (гелия) и водорода составляла $40 \mathrm{~cm}^{3} /$ мин, воздуха - $300 \mathrm{~cm}^{3} /$ мин [5].

Пики метиловых эфиров жирных кислот идентифицировали по времени удерживания на колонке и в сравнении со стандартным набором К-101 Mixture Zot 1314 («Sigma», США), содержащим метиловые эфиры каприновой (C10:0), лауриновой (C12:0), миристиновой (C14:0), пальмитиновой (C16:0), стеариновой (C18:0) и арахиновой (С20:0) кислот. Кроме того использовали смесь метиловых эфиров пальмитиновой (C16:0), стеариновой $(\mathrm{C} 18: 0)$, олеиновой $(\mathrm{C} 18: 1)$ и линолевой $(\mathrm{C} 18: 2)$ кислот («Serva», Германия). Содержание жирных кислот выражали в относительных величинах, рассчитывали по площади пиков и выражали в \% от суммы площадей всех обнаруженных кислот по показаниям детектора прибора.

Все определения проводили в двух биологических и двух аналитических повторностях. В таблицах и на графиках представлены данные одного из типичных опытов в виде средних арифметических значений и их стандартных отклонений.

\section{Обсуждение результатов}

В табл. 1 приведены результаты анализа свободных жирных кислот проростков кукурузы, образование которых связано с превращением фосфолипидов. Было установлено, что среди свободных жирных кислот присутствуют практически те же кислоты, которые характерны для фосфолипидов растительных клеток [6]. Исключение составила олеиновая кислота, которая была обнаружена лишь в следовых количествах (рис. 1). Доминирующими среди свободных жирных кислот проростков кукурузы из насыщенных были пальмитиновая, из ненасыщенных - пальмитолеиновая (23.5 и 16.11\% от суммы кислот, соответственно) кислоты. Обработка растений кинетином вызывала изменения среди свободных жирных кислот проростков, но не затрагивала их качественного состава. Уровень линолевой кислоты под действием кинетина практически не менялся, однако увеличилось содержание другой ненасыщенной кислоты - пальмитолеиновой (до 18.8\% от суммы). Среди насыщенных свободных жирных кислот также произошли определенные изменения, которые выразились в увеличении содержания миристиновой и стеариновой кислот и уменьшении количества пальмитиновой кислоты. Однако наблюдаемые изменения значительно не отразились на уровне ненасыщенности $(\mathrm{u} / \mathrm{s})$ фонда свободных жирных кислот клетки, величина которой составила 0.50 (табл.2). 
Таблица 1. Свободные жирные кислоты проростков кукурузы при действии кинетина и различных условий газового состава среды (\% от суммы)

\begin{tabular}{|c|c|c|c|c|c|c|}
\hline \multirow{2}{*}{ Вариант } & \multicolumn{6}{|c|}{ Жирные кислоты } \\
\hline & 14:0 & $16: 0$ & $16: 1$ & 18:0 & $18: 2$ & $20: 0$ \\
\hline \multicolumn{7}{|c|}{ Воздух (контроль) } \\
\hline Воздух & $\begin{array}{c}14.14 \pm \\
1.12\end{array}$ & $\begin{array}{c}23.53 \pm \\
0.20\end{array}$ & $\begin{array}{c}16.11 \pm \\
1.82\end{array}$ & $\begin{array}{c}9.85 \pm \\
0.72\end{array}$ & $14.47 \pm 0.43$ & $\begin{array}{l}6.33 \pm \\
0.22 .\end{array}$ \\
\hline + кинетин & $\begin{array}{c}19.76 \pm \\
0.13\end{array}$ & $\begin{array}{c}19.61 \pm \\
0.31\end{array}$ & $\begin{array}{c}18.78 \pm \\
0.24\end{array}$ & $16.33 \pm 0.42$ & $14.42 \pm 0.21$ & $\begin{array}{c}11.13 \pm \\
0.44\end{array}$ \\
\hline \multicolumn{7}{|c|}{ Гипоксия } \\
\hline Гипоксия & $\begin{array}{c}12.77 \pm \\
0.44\end{array}$ & $\begin{array}{c}23.15 \pm \\
0.32\end{array}$ & $\begin{array}{c}17.42 \pm \\
0.42\end{array}$ & $\begin{array}{c}9.91 \pm \\
0.41\end{array}$ & $18.43 \pm 0.72$ & $\begin{array}{c}8.95 \pm \\
0.25\end{array}$ \\
\hline + кинетин & $\begin{array}{c}10.11 \pm \\
0.80\end{array}$ & $\begin{array}{c}26.16 \pm \\
1.33 \\
\end{array}$ & $\begin{array}{c}20.25 \pm \\
0.52\end{array}$ & $\begin{array}{c}8.33 \pm \\
0.73\end{array}$ & $14.06 \pm 0.26$ & $\begin{array}{c}10.37 \pm \\
0.98\end{array}$ \\
\hline \multicolumn{7}{|c|}{$\mathrm{CO}_{2}$-среда } \\
\hline $\mathrm{CO}_{2}$-среда & $\begin{array}{c}10.50 \pm \\
0.40\end{array}$ & $\begin{array}{c}18.95 \pm \\
0.20\end{array}$ & $\begin{array}{c}18.48 \pm \\
0.94\end{array}$ & $\begin{array}{c}6.95 \\
\pm 0.63\end{array}$ & $21.11 \pm 0.33$ & $\begin{array}{c}9.73 \\
\pm 0.53\end{array}$ \\
\hline + кинетин & $\begin{array}{c}13.14 \pm \\
0.32\end{array}$ & $\begin{array}{l}24.54 \\
\pm 0.52\end{array}$ & $\begin{array}{c}19.33 \pm \\
0.32\end{array}$ & $\begin{array}{c}7.51 \pm \\
0.32\end{array}$ & $12.75 \pm 0.95$ & $\begin{array}{c}8.17 \pm \\
0.24\end{array}$ \\
\hline
\end{tabular}
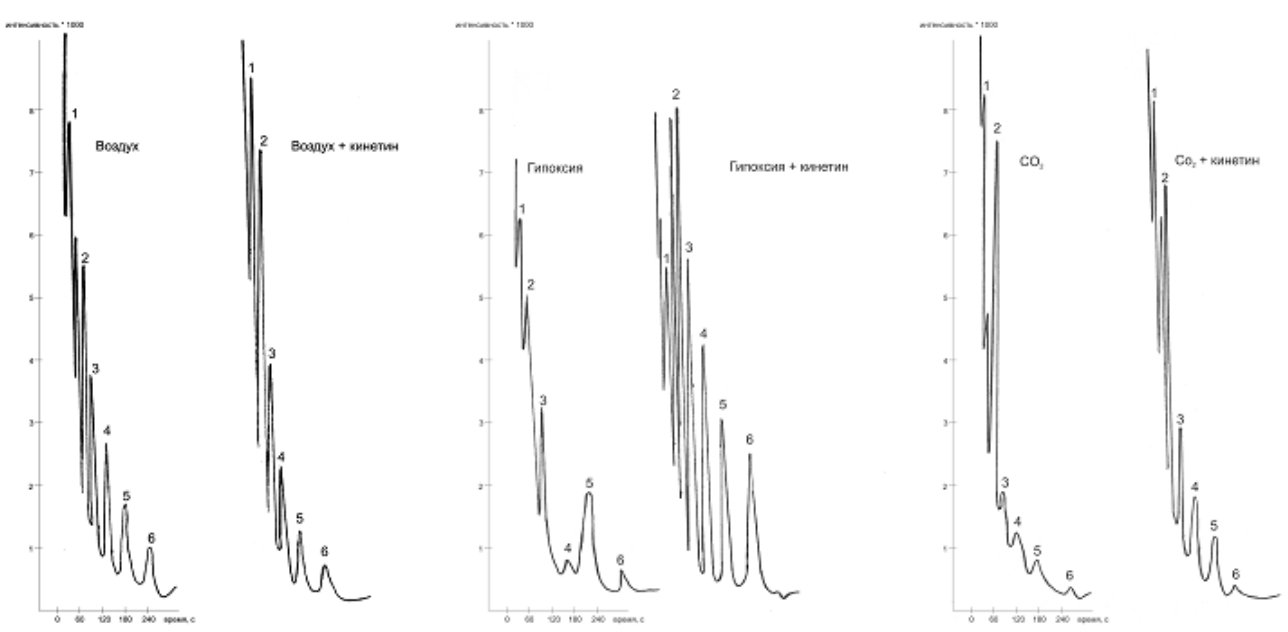

Рис. 1. Хроматограмма свободных жирных кислот проростков кукурузы при действии разных газовых сред: 1 - миристиновая (С 14:0), 2 - пальмитиновая (C16:0), 3 пальмитолеиновая (C16:1), 4 - стеариновая (C18:1), 5 - линолевая (C18:2), 6 - арахиновая (C20:0): $\mathrm{A}$ - воздух; $\mathrm{B}$ - гипоксия, $\mathrm{C}-\mathrm{CO}_{2}$-среда

Таблица 2. Влияние кинетина и газового состава среды на состав и распределение свободных жирных кислот проростков кукурузы (\% от суммы)

\begin{tabular}{|c|c|c|c|c|c|}
\hline \multirow[b]{2}{*}{ Вариант } & \multicolumn{5}{|c|}{ Жирные кислоты } \\
\hline & $\begin{array}{c}\text { насыщен- } \\
\text { ные (S) }\end{array}$ & $\begin{array}{c}\text { ненасыщен- } \\
\text { ные (U) }\end{array}$ & $\mathrm{U} / \mathrm{S}$ & моноено-вые & диеновые \\
\hline \multicolumn{6}{|c|}{ Воздух (контроль) } \\
\hline Воздух & 53.67 & 30.58 & 0.57 & $16.11 \pm 0.72$ & $14.47 \pm 0.43$ \\
\hline+ кинетин & 66.81 & 33.26 & 0.50 & $18.78 \pm 0.24$ & $14.42 \pm 0.21$ \\
\hline \multicolumn{6}{|c|}{ Гипоксия } \\
\hline Гипоксия & 59.76 & 35.85 & 0.60 & $17.42 \pm 0.42$ & $18.43 \pm 0.72$ \\
\hline + кинетин & 54.85 & 34.31 & 0.62 & $20.25 \pm 0.52$ & $14.06 \pm 0.26$ \\
\hline \multicolumn{6}{|c|}{$\mathrm{CO}_{2}$-среда } \\
\hline $\mathrm{CO}_{2}$-среда & 54.83 & 39.59 & 0.79 & $18.48 \pm 0.94$ & $21.11 \pm 0.33$ \\
\hline + кинетин & 59.10 & 32.08 & 0.54 & $19.33 \pm 0.32$ & $12.75 \pm 0.95$ \\
\hline
\end{tabular}


В условиях модифицированных газовых сред у растений произошли существенные сдвиги в содержании отдельных свободных жирных кислот. В условиях гипоксии и, особенно при действии $\mathrm{CO}_{2}$-среды, наблюдали накопление ненасыщенных жирных кислот (пальмитолеиновой и, особенно, линолевой), что привело к увеличению показателя уровня их ненасыщенности $(\mathrm{u} / \mathrm{s})$ до 0.60 и 0.79 соответственно. Наблюдаемое увеличение содержания ненасыщенных свободных жирных кислот совпадает с уменьшением их количества в фосфолипидах, как это было показано ранее [7]. Это позволяет предположить, что в условиях гипоксии, и особенно $\mathrm{CO}_{2}$-среды, у растений тормозится не столько синтез, сколько усиливается деструктивный распад фосфолипидов.

Предобработка растений кинетином препятствовала наблюдаемым изменениям в содержании свободных жирных кислот у растений, помещенных в условия модифицированных газовых сред, и практически полностью предотвращала накопление линолевой кислоты. При этом под действием кинетина увеличивалось содержание моноеновых ненасыщенных жирных кислот на фоне падения содержания диеновых кислот. Это привело к снижению ненасыщенных свободных жирных кислот $(\mathrm{u} / \mathrm{s})$ до 0.60 и 0.54 и это было близко к аэрируемым растениям. Полученные данные подтверждают наше предположение о том, что защитное действие кинетина может быть связано со способностью этого фитогормона предотвращать распад фосфолипидов, вызванный действием на растения неблагоприятных факторов среды. Надо отметить, что стабилизирующее действие кинетина проявлялось у проростков, находящихся как в условиях обычной гипоксии, так и при действии высоких концентраций диоксида углерода. Это показывает, что действие высоких концентраций диоксида углерода на обмен жирных кислот является легко обратимым и снимается обработкой растений фитогормоном кинетином или возвращением в условия нормальной аэрации [6].

\section{Заключение}

Как известно, жирные кислоты липидов растений наиболее чутко реагируют на воздействие разных факторов внешней среды и их метаболизм находится в прямой зависимости от ее газового состава $[8,9]$. В наших опытах у проростков кукурузы были отмечены изменения степени ненасыщенности (u/s) свободных жирных кислот за счет увеличения содержания кислот C:16 и C:18-ряда ри действии как условий дефицита кислорода, так и среды высоких концентраций диоксида углерода. Это выражалось в увеличении содержания пальмитолеиновой и, в меньшей степени , линолевой кислот. Мы предполагаем, что это связано с деструкцией фосфолипидов, а не с торможением их синтеза. Подобные данные были получены нами ранее при анализе фосфолипидов мембран кукурузы в условиях гипоксического стресса [7]. В то же время нельзя исключать и влияние газовой среды на процессы межмолекулярного обмена между фондом свободных жирных кислот и жирнокислотными компонентами различных групп липидов, включая и фосфолипиды, как это предполагалось рядом исследователей. [5]. Ранее было обнаружено, что при кратковременном воздействии анаэробного стресса может снижаться удельная активность липоксигеназы у проростков сои, обладающей определенной устойчивостью к недостатку кислорода [10],чем у менее устойчивых проростков гороха [9]. Максимальное подавление активности этого фермента было отмечено при 24-часовом действии анаэробиоза. Можно предположить, что значительная активация ПОЛ у проростков кукурузы, наблюдаемая в этот период особенно при действии на растения $\mathrm{CO}_{2}$, могло быть результатом не усиления ферментативной части ПОЛ, а следствием активации

Eршова и др. / Сорбционные и хроматографические процессы. 2019. Т. 19. № 6. С. 735-741 
у этих растений неферментативных свободнорадикальных процессов перекисного окисления [11]. Усиление образования свободных радикалов при гипоксии путем неферментативных реакций ПОЛ отмечали ранее у неустойчивых к затоплению видов растений [12 ].

Обработка растений кинетином препятствовала наблюдаемым изменениям в содержании свободных жирных кислот у растений, помещенных в условиях разных газовых сред, практически полностью предотвращала накопление среди свободных жирных кислот линолевой кислоты. Это подтверждает наше предположение о том, что защитное действие кинетина может быть связано со способностью этого фитогормона предотвращать распад фосфолипидов, вызванный действием на растения неблагоприятных факторов среды. Подобного мнения придерживаются и другие авторы [3] показавшие, что цитокинины препятствуют образованию у растений свободных радикалов, таких как супероксид и жирные кислоты. Ранее нами было показано [6], что кинетин, так же как и фитогормон эпибрассинолид. влияли на скорость образования диеновых коньюгатов ненасыщенных жирных кислот, образование которых является чувствительным тестом на появление гидроперекисей жирных кислот. Снижение под действием кинетина и ЭБ содержания диеновых коньюгатов и МДА наблюдали для проростков кукурузы, что может быть связано с торможением под действием используемых фитогормонов процессов перекисного окисления липидов. Это позволяет предположить, что действие кинетина на растения, находящиеся в условиях дефицита кислорода, может быть обусловлено влиянием фитогормонов не только на распад, но и на процессы перекисного окисления свободных и связанных в фосфолипидах жирных кислот. Таким образом, показано, что кинетин препятствует распаду фосфолипидов и накоплению свободных жирных кислот, а также их перекисному окислению, что ранее только предполагалось [3].

Нужно отметить, что $\mathrm{CO}_{2}$-среда обладала специфическим действием на метаболизм растений, которое было связано не только с созданием анаэробных условий. Диоксид углерода, как активный компонент клеточного обмена, при высоких концентрациях был способен выступать в роли регулятора активности некоторых ферментов [6], а также влиять на жирнокислотные компоненты липидов и свободные жирные кислоты. Защитное действие кинетина на растения в варианте со средой $\mathrm{CO}_{2}$, как видно из результатов опыта, так же было выражено более значительно, чем в условиях обычной гипоксии. Это подтверждает обратимость действии диоксида углерода на метаболизм растений, что позволяет отнести его к активным низкомолекулярным регуляторам обменных процессов растений в условиях дефицита кислорода.

\section{Список литературы}

1. Веселов Д.С., Кудоярова Г.В., Кудоярова Н.В., Кузнецов В.В. // Физиология растений. 2017. Т. 64. № 1. С.19-32.

2. Ershova A.N., Vinokurova N.V. // International Journal of Secondary Metabolite (IJSM). 2018. Vol. 5. No. 2 pp. 156-162.

3. Leshem Y.Y. // Canad. J. Bot. 1984.V.62. No 12. pp. 2943-2949.

4. Harwood J.L. // Ann. Rev. Plant Physiol. and Plant Mol. Biol., 1988, Vol. 39. pp. 101138.
5. Ершова А.Н., Тюрина И.В // Сорбционные и хроматографические процессы. 2018. T.18. № 6. C.927-933.

6. Ершова А.Н. Метаболическая адаптация растений к гипоксии и повышенному содержанию диоксида углерода. Воронеж. Воронеж. гос. ун-т. 2007. 264 с.

7. Землянухин А.А., Ершова А.Н. // Доклады АН СССР. 1986. Т. 281. № 3. С. 762764. 
8. Vartapetian B.B., Andreeva I.N., Generozova I.P., Polyakova L.I et al. // Annals of Bota$n y, 2003$. Vol. 91. No 2. pp. 155-172.

9. Ершова А.Н., Бердникова О.С. // «Механизмы устойчивости растений и микроорганизмов к неблагоприятным условиям среды», сборник материалов Всерос. конференции с междунар. участием, 10-15 июля 2018г., Иркутск. 2018. С. 312-315.

\section{References}

1. Veselov D.S., Kudoyarova G.V., Kudoyarova N.V., Kuznetsov V.V., Fiziologiya rasteniy, 2017, Vol. 64, No 1, pp. 19-32. DOI:10.7868/S00153031701016X Available at: www.rusplant.ru

2. Ershova A.N., Vinokurova N.V., International Journal of Secondary Metabolite (IJSM), 2018, Vol. 5, No 2, pp. 156-162. DOI: 10.21448/ijsm.422077 Available at: www.ijate.net/index.php/ijsm

3. Leshem Y.Y., Canad. J. Bot., 1984, Vol. 62, No 12, pp. 2943-2949.

4. Harwood J.L., Ann. Rev. Plant Physiol. and Plant Mol. Biol., 1988, Vol. 39, pp. 101-138.

5. Ershova A.N., Tyurina I.V., Sorbtsionnye i khromatograficheskie protsessy, 2018, Vol. 18, No 6, pp. 927-933. DOI: https://doi.org/10.17308/sorpchrom.2018.18/62 2, Available at: www journals.vsu.ru/sorpchrom

6. Ershova A.N. Metabolicheskaya adaptatsiya rastenij $k$ gipoksii i povyshennomu soderzhaniyu dioksida ugleroda. Voronezh, Voronezh State Univ. Publ., 2007, 264 p.

Ершова Антонина Николаевна - професcop, д.б.н., заведующая кафедрой биологии растений и животных, Воронежский государственный педагогический университет, Воронеж

Стерлигова Ирина Александровна - студент, Воронежский государственный университет, Воронеж
10. Maccarrone M., Veldink G.A., Vliegenthart J.F.G. // FEBS. Lett. 1991. Vol. 291. No 1. pp. 117-121.

11. Ершова А.Н., Попова Н.В..Бердникова О.С. // Физиология растений. 2011. Т.58. № 6. C. $834-843$.

12. Crawford R.M.M. // Agrochimica. 1985. Vol. 29. No 1. pp. 51-63.

7. Zemlyanukhin A.A., Ershova A.N., Proceedings of USSR Academy of Science, 1986, Vol. 281, No 3, pp. 762-761

8. Vartapetian B.B., Andreeva I.N., Generozova I.P., Polyakova L.I. et al., Annals of Bota$n y$, 2003, Vol. 91, No 2, pp. 55-172. DOI: 10.1093/aob/mcf244, available at: www.aob.oupjournals.org

9. Ershova A.N., Berdnikova O.S. «Mechanisms of resistance of plants \& microorganisms to unfavorable environmental», Proceedings of All-Russian Scientific Conference with International Participation, July 10-15, 2018, Irkutsk, 2018, pp. 312-315. DOI: 1031255 / 978-594797-319-8-312-315, available at: www.sifibr.irk.ru

10.Maccarrone M., Veldink G.A., Vliegenthart J.F.G., FEBS. Lett., 1991, Vol. 291, No 1, pp. 117-121.

11.Ershova A.N., Popova N.V., Berdnikova O.S., Fiziologiya rasteniy, 2011, Vol. 58, No 6, pp. 834-843.

12.Crawford R.M.M., Agrochimica, 1985, Vol. 29, No 1, pp. 51-63.

Ershova Antonina N. - professor, grand $\mathrm{PhD}$ (biology), department of plant and animal biology Chair, Voronezh State Pedagogical University, Voronezh, email: aershova@vspu.ac.ru

Sterligova Irina A. - student, Voronezh State University, Voronezh 